\title{
Former health secretary takes on another advisory role in private health sector
}

Clarification - In this News story (BMJ 2015;351:h6201, doi:10. 1136/bmj.h6201), Gareth Iacobucci wrote that the former health secretary for England, Andrew Lansley, "has taken on a role advising the drug company Roche, prompting fresh concerns over the 'revolving door' between the government and industry." A spokesman for Roche has contacted us with the following statement: "Andrew Lansley has only undertaken a total of one day's consultancy work for Roche since he was appointed to the House of Lords, and we have no further plans to use Andrew Lansley again." We are happy to publish this clarification.

\section{Cite this as: BMJ 2015;351:h6459}

๑ BMJ Publishing Group Ltd 2015 